\title{
Study on permanent tubal sterilisation in a semi-urban based medical college hospital
}

\section{Kanmani K.*, Rani P.R., Gokulakrishnan G.}

Department of OBG, Government Vellore Medical College, Adukkamparai, Vellore, Tamilnadu, India

Received: 22 May 2016

Accepted: 27 May 2016

\section{*Correspondence:}

Dr. Kanmani K.,

E-mail: s.k.samy40@gmail.com

Copyright: () the author(s), publisher and licensee Medip Academy. This is an open-access article distributed under the terms of the Creative Commons Attribution Non-Commercial License, which permits unrestricted non-commercial use, distribution, and reproduction in any medium, provided the original work is properly cited.

\section{ABSTRACT}

Background: Tubal sterilisation is a permanent method of contraception in use for many years. Main objective of our study is to find the acceptance of permanent method of tubal sterilisation in women delivering in a semi-urban based medical college hospital.

Methods: Retrospective analysis was carried to find the number of women undergoing tubal sterilisation in our hospital for period of one year from April 2015 to March 2016.

Results: Total women delivered over a period of one year were 10959 out of them 2619 women underwent tubal sterilisation. Analysis showed acceptance was high when combined with lower segment cesarian section (LSCS) and more among women in the age of 20-29 years.

Conclusions: The present study showed the acceptance of tubal sterilisation following vaginal delivery to undergo mini lap is still low compared to concurrent sterilisation with LSCS. High order births are still prevalent in semiurban based hospitals. Not only motivation, also regular review of registers that update the eligible couples, identification of complications and timely referral to higher centers will help in achieving the goal of bringing down the number of high order birth which in turn will reducing the maternal and perinatal mortality and morbidity.

Keywords: Tubal sterilisation, Permanent contraception, Modified pomeroy technique

\section{INTRODUCTION}

The first female sterilisation was performed in North America by S.S.Lungren at the time of caesarean section in 1880. For the next few decades all tubal sterilisation were performed at the time of laparotomy as concurrent procedure because the risk of mortality was too high to perform this procedure alone. In 1970, tubal sterilisation became widespread due to introduction of minilap and laparoscopy methods. Sterilisation is the most commonly used method of family planning in the world. ${ }^{1-2}$ Physical and mental health of a child depends on responsible and planned parenthood which is possible only by adopting any of the contraceptive methods available. This Study on permanent tubal sterilisation in a semi-urban based medical college hospital throws light on various parameters influencing the acceptance. Undergoing tubal sterilisation with two living children irrespective of the sex of the child will help in reducing high order birth and its complications which in turn reduces the maternal and perinatal mortality and morbidity. ${ }^{3-8}$

\section{METHODS}

This is a retrospective study conducted at Government Vellore Medical College Hospital which is a semi urban based hospital at Adukkamparai, Vellore, Tamilnadu, India from April 2015 to March 2016 for a period of one year. Source of data was collected from maternity department and family planning department is our hospital. 


\section{Inclusion criteria}

- $\quad$ Age of the women should be more than 21 and less than 44 years.

- Women who fulfil the medical eligibility criteria were taken up for the procedure. Sterilisation requires informed consent stating that it is a permanent procedure and rare possibility of failure should be explained to the couple during the antenatal period. Women undergoing sterilisation needs to give written consent. Though the consent of the spouse is not mandatory, our women do not accept unless the spouse and family members support their decision.

\section{Exclusion criteria}

Usually not done in women who have an unstable medical condition like hemorrhage, severe anaemia, heart disease (not fit for surgery), infection, uncontrolled hypertension, HELLP (haemolysis, elevated liver enzymes, and low platelets) syndrome. In women with unstable mind where their consent is not mature according to local/state regulations special committee should decide about the procedure. Paediatrician refusal when the status of new-born is unstable.

\section{Timing of sterilisation and method}

It is done within 48 hours or within 7 days following child birth or along with caesarean section. It can also be done following menstruation and immediately following abortion or within 48 hours.

\section{Route of sterilisation}

Mini laparotomy, laparoscopy, hysteroscopy, culdotomy are the methods available. The first two methods are commonly followed due to lesser complications.

\section{Technique}

Modified Pomeroy's technique is followed.1cm is excised in the isthmal area of tube and cut ends are tied. Laparoscopic sterilisation is done following menstruation or following abortion within 48 hours or 6 weeks after delivery, (after excluding pregnancy) by applying fallope rings on either side of tube after confirming that it is the tube and not the round ligament by looking at the fimbrial end.

\section{RESULTS}

During our one year study period from April 2015 to March 2016, 10959 women delivered, out of which 4868 were Para 2 and above and eligible for permanent tubal sterilisation methods. Out of the eligible couples $4868(100 \%)$ Total numbers of tubal sterilisations were $2619(53.8 \%)$ remaining women 2249 (46.2\%) adopted temporary methods of contraception. Comparing the total deliveries in relation with parity and the number of women who accepted tubal sterilisation shows highest percentage with para 3 (Table 1, Figure 1).

Out of the women who underwent tubal sterilisation $2619(100 \%)$ parity wise acceptance of tubal sterilisation was $1959(74.7 \%)$ with para 2, $540(20.6 \%)$ with para 3, and $110(4.2 \%)$ with para 4 and above. $10(0.4 \%)$ women with one child underwent tubal ligation. Age wise analysis showed the acceptance to be high with 20 to 29 years age (Table 2, Figure 2).

Analysing the different methods of tubal sterilisation, LSCS with sterilisation were 1694 (64.7\%) puerperal sterilisation were $662(25.3 \%)$, laparoscopic sterilisation were $71(2.7 \%)$, MTP with sterilisation were $91(3.4 \%)$, and TAT were $101(3.9 \%)$. LSCS with sterilisation $64.7 \%$ contribute the most (Table 3, Figure 3).

Table 1: Acceptance of tubal sterilisation.

\begin{tabular}{|lll|}
\hline & Total delivery & Total sterilisation \\
\hline Para 1 & 6091 & 10 \\
\hline Para 2 & $3804(100 \%)$ & $1959(51.4 \%)$ \\
\hline Para 3 & $878(100 \%)$ & $540(61.5 \%)$ \\
\hline Para 4 & $186(100 \%)$ & $110(59.1 \%)$ \\
\hline Total & 10959 & 2619 \\
\hline
\end{tabular}

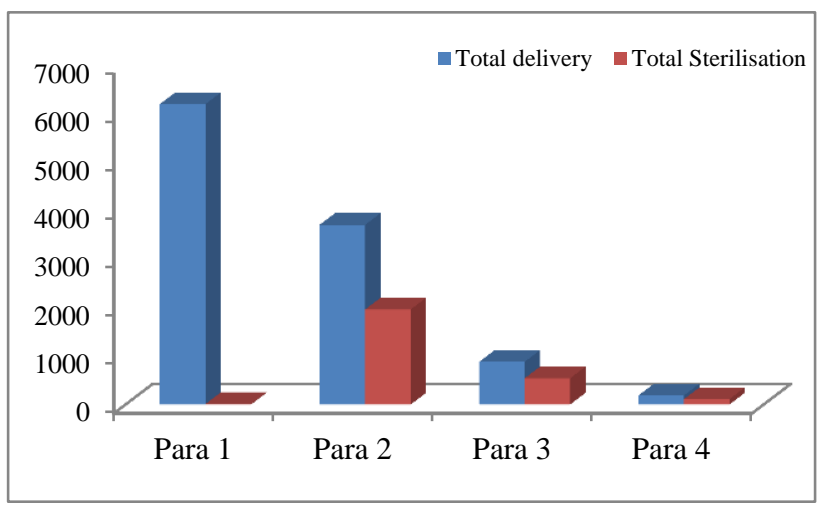

Figure 1: Parity wise acceptance of tubal sterilisation.

Table 2: Age wise acceptance of temporary and permanent methods of sterilisation.

\begin{tabular}{|lll|}
\hline Age wise & PPIUCD & Sterilisation \\
\hline$<19$ & 365 & 0 \\
\hline $20-29$ & 6167 & 2289 \\
\hline 30 and above & 1018 & 330 \\
\hline Total & 7550 & 2619 \\
\hline
\end{tabular}

Table 3: Different methods of sterilisation.

\begin{tabular}{|lllll|}
\hline PS & TAT & $\begin{array}{l}\text { LSCS } \\
\text { with ST }\end{array}$ & $\begin{array}{l}\text { MTP with } \\
\text { TAT }\end{array}$ & $\begin{array}{l}\text { Lap } \\
\text { sterilisation }\end{array}$ \\
\hline 662 & 101 & 1694 & 91 & 71 \\
\hline
\end{tabular}




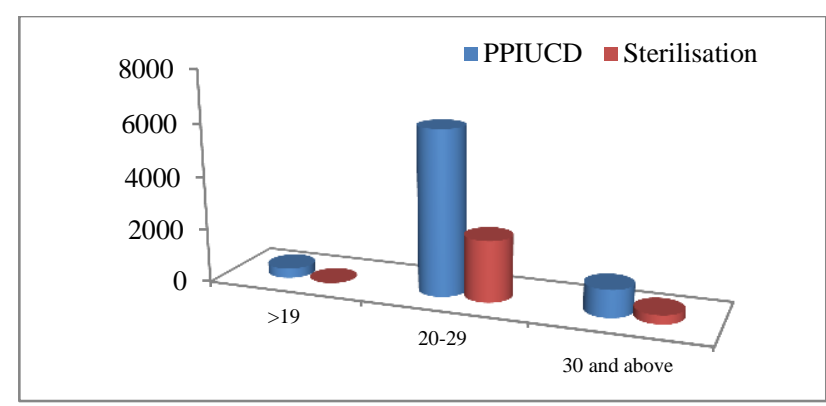

Figure 2: Age wise acceptance of temporary and permanent methods of sterilisation.

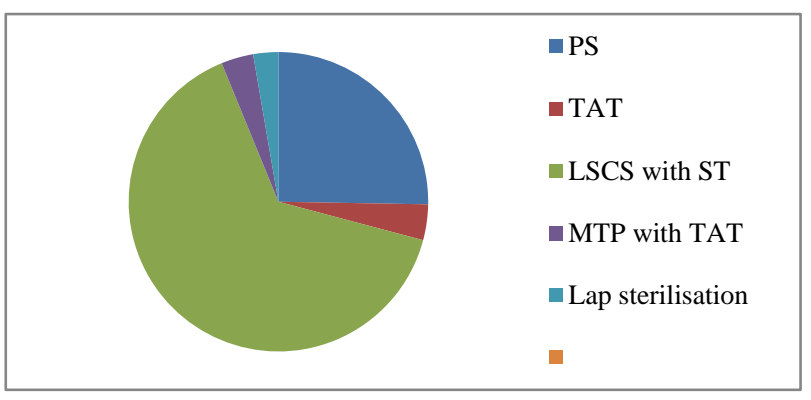

Figure 3: Different methods of sterilisation.

\section{DISCUSSION}

Those who undergo LSCS the acceptance rate is high because there is no need for separate surgery, whereas those with 2 normal deliveries accepted the temporary method. Age wise acceptance was high in 20-29 years of age. Among female sterilization methods puerperal sterilization contributed the most. Those with 2 children refused due to various factors like the children were of the same sex, had fear about the surgery, the $2^{\text {nd }}$ child of lower birth weight, need for extra stay in the hospital etc., Sometimes paediatrician fitness could not be obtained due to low birth weight and anaesthetist fitness could not be obtained due to medical disorders like heart disease, pre-eclampsia, anaemia, diabetes, which does not return to normal within the stipulated time of 7 days within delivery. Almost $40 \%$ of the women with even three and four children did not undergo tubal sterilization. PPIUCD was inserted for these women if they are not willing for permanent method. Those who undergo LSCS the acceptance rate is high because there is no need for separate surgery, whereas those with 2 normal deliveries accepted the temporary method. Age wise acceptance was high in 20-29 years of age.

Connell et al in his overview on postpartum tubal sterilization states that most of the cases were done after caesarean section which very well correlates with our study. ${ }^{1}$ Sheethal et al in their study stated that modified pomeroy technique was the most commonly performed method of tubal sterilization which is followed in our study. $^{2}$

Among female sterilization methods puerperal sterilization following vaginal delivery or concurrent with LSCS contributed the most.

\section{CONCLUSION}

Tubal sterilisation is the most commonly performed permanent method of family planning all over the world. The current approach in family planning emphasizes on offering high quality contraceptive services among eligible clients on voluntary basis. Our study shows that the coverage rate is still low in semi urban based areas where the need for motivation for the acceptors and the providers has to be improved a lot. Not only timely correction of medical disorders so that the surgery can be performed within 7 days of delivery also timely referral for MTP with TAT will help in reducing the high order births and its complications.

\section{Funding: No funding sources}

Conflict of interest: None declared

Ethical approval: The study was approved by the Institutional Ethics Committee

\section{REFERENCES}

1. Postpartum tubal sterilisation: overview, technique, periprocedural care. Available at http:// emedicine.medscape.com/ article/1848524-overview. Accessed on 16 March 2016.

2. Madari S, Varma R, Gupta J. A comparison of the modified pomeroy tubal ligation and filshie clips for immediate postpartum sterilisation: a systematic review. Eur J Contracept Reprod Health Care. 2011;16(5):341.

3. Lawrie TA, Kulier R, Nardin JM. Techniques for the interruption of tubal patency for female sterilisation. Cochrane Database Syst Rev. 2015;9:CD003034.

4. Access to postpartum sterilization. Committee opinion. American College of Obstetricians and Gynaecologists. Obstet Gynecol. 2012;120:212-5.

5. American college of obstetricians and gynaecologists. Tubal ligation with caesarean delivery. ACOG Committee Opinion 205. Washington, DC. ACOG;1998:(Level III).

6. Moaddab A, Mccullough LB, Chervenak FA, et al. Health care justice and its implications for current policy of a mandatory waiting period for elective tubal sterilization. Am J Obstet Gynecol. 2015;212(6):736-9.

7. Peterson HB, Xia Z, Hughes JM, Wilcox LS, Tylor LR, Trussell J. The risk of pregnancy after tubal sterilization: findings from the U.S. Collaborative review of sterilization. Am J Obstet Gynecol. 1996.174(4):1161-8.

8. ACOG Practice Bulletin No. 46. Benefits and risks of sterilization. September 2003.

Cite this article as: Kanmani K, Rani PR, Ganesh G. Study on permanent tubal sterilisation in a semiurban based medical college hospital. Int J Reprod Contracept Obstet Gynecol 2016;5:1736-8. 